\title{
OPTIMALISASI NILAI TAMBAH DAN DIGITAL MARKETING PADA PRODUK OLAHAN BLIMBING DI DESA KALANGAN NGUNUT
}

\author{
Nailariza Umami, Maria Aghata Sri. W.H, Novita Eka Muliawati \\ Universitas Bhinneka PGRI \\ umaminailarizaumami@gmail.com, mariaaghata@stkippgritulungagung.ac.id, \\ novita@stkippgritulungagung.ac.id
}

\begin{abstract}
The purpose of this social service was to optimize the potential development of fresh star fruits by increasing the added value to increase innovation of star fruit processed products, brand and marketing strategies through digital marketing in Kalangan Village, Ngunut District. The methods used in this community service activity were lectures, discussions, demonstrations, and direct practice. The work plan was programmed in 2 month. The results of this service activity are the increasing knowledge of community groups in Kalangan Ngunut Village in terms of digital marketing and innovation of starfruit processed products. Besides, people in Kalangan Ngunut village can directly practice digital marketing to promote starfruit products. In addition, they also can apply innovations to process fresh starfruit into processed products in the form of starfruit dates as well as package and label the product into more interesting way. In addition, the activities also increase public awareness to always improve innovation and strategies in building entrepreneurship in order to help their businesses to survive during the COVID-19 pandemic.
\end{abstract}

Keywords: star fruit product innovation, branding, digital marketing

\section{ANALISIS SITUASI}

Diakhir juli 2020, kementrian ketanagakerjaan (Kemnaker) mencatat jumlah pekerja yang terkena Pemutusan Hubungan Kerja (PHK) serta yang dirumahkan mencapai 3.5 juta lebih. Selain itu dari data Badan Penyelenggara Jaminan Sosial (BPJS) sampai dengan bulan Juli ada sekitar 1.1 juta orang yang di rumahkan. Sebanyak 380.000 orang terkena Pemutusan Hubungan Kerja (PHK), dan kurang lebih 630.000 orang pekerja sektor informal terkena imbas Covid 19. Hal ini menambah tantangan pembangunan ketangakerjaan menjadi semakin kompleks. Karena akibat yang ditibulkan Covid-19 terhadap perekonomian akhirnya juga berimbas kepada para pekerja, terutama pada empat sektor utama perekonomian Indonesia yaitu pariwisata, perdagangan, manufaktur serta pertanian.
Bank Indonesia menyampaikan sejumlah 87,5 persen UMKM terdampak pandemi Covid-19. Dari jumlah ini sekitar 93,2 persen diantaranya terdampak negatif pada sisi penjualan . Dari survei yang dilakukan bank sentral, pandemi memberi tekanan pada pendapatan, keuntugan ,dan arus kas hingga para pemilik usaha memilih untuk wait and see. Hal ini mengakibatkan usaha rakyat makin melemah akhirnya sektor UMKM menjadi terpuruk .

Padahal sesuai yang disampaikan Badan Pusat Statistik (BPS) banyaknya UMKM yang tercatat pada tahun 2018 sebanyak 64.94.057 atau sebanyak 99,9\% dari semua unit penjualan yang ada di Indonesia. Ditinjau dari data tersebut menandakan bahwa UMKM mendapat kontribusi yang besar dalam menciptakan laju pertumbuhan ekonomi menjadi sumber pendapatan bagi masyarakat dan penyedia 
lapangan pekerjaan untuk banyak tenaga kerja.

Sehingga perlu penguatan atau pemberdayaan UMKM agar lebih berkembang serta bisa mendukung kestabilan perekonomian nasional. Pemberdayaan UMKM adalah langkah strategis untuk menaikkan produktifitas dan memajukan serta mengembagkan sektor UMKM itu sendiri. Usaha yang dilakukan agar dapat memberdayakan UMKM adalah dengan mengoptimalkan nilai tambah yaitu dengan meningkat produk dan branding.

Hal lain yang perlu dilakukan pula adalah perluasan pemasaran produk karena sebenarnaya UMKM di Indonesia sulit berkembang. Salah satu penyebabnya adalah skala pemasaran yang masih sempit. Digital marketing merupakan salah satu bentuk strategi pemasaran yg dilakukan untuk mepromosikan produk agar bisa sampai kepada konsumen secara cepat dan tepat waktu. Saat ini masih sedikit UMKM di Indonesia yang menggunakan digital marketing untuk media pemasaran. Faktanya diera kini transaksi jual beli sudah banyak menggunakan digital marketing, sebab dirasa lebih memudahkan baik bagi konsumen maupun untuk penjual itu sendiri. Penjual bisa menjangkau pasar yg lebih luas dan untuk konsumen dapat membandingkan harga antar satu penjual dan penjual lainnya.

Melihat semakin berkembangnya zaman diikuti dengan berkembang pesatnya teknologi. Memancing munculnya tren baru dalam dunia pemasaran khususnya Digital Marketing. Digital marketing sendiri adalah suatu kegiatan pemasaran yang dilakuka melalui platform digital. Tren pemasran berpindah dari konvesional (offline) dan sekarang digital (online). Konsep Digital Marketing yg dipakai oleh para pelaku usaha adalah melakukan pemasaran produknya dari mana saja dan kapan saja melalui internet .

Digital marketing terbukti cara terbaik memanfatkan era dunia digital dengan media online dalam membangun pekerjaan di perusahaan atau dalam berbisnis. Dalam kondisi sekarang pandemi Covid-19 yang mengharuskan untuk menjalankan aktivitas dalam media online seperti contohnya mereka yang bekerja di rumah atau WFH (Work From Home). Berdasarkan statistik, penduduk Indonesia maupun luar negeri menghasilkan hingga $80 \%$ kesehariannya di aplikasi mobile membuat smartpone mendominasi saluran komunikasi. Seiring berjalannya waktu, di dunia perusahaan memang diharuskan menerapkan sistem digital marketing untuk menarik pembeli atau konsumen.

Desa Kalangan yg terletak di kecamatan Ngunut ini memiliki potensi besar dalam budidaya buah belimbing. Sebagian besar bibit tanaman belimbing manis lokal yang dikembangkan, adalah jenis Sembiring dan Blantong, sedangkan Bangkok Merah, Dewi dan Madu digunakan untuk memperbaiki kualitas buah . Biasanya proses perbaikan tanaman petani sudah dilatih oleh petugas penyuluh pertanian setempat dengan cara disambung atau grafting. Petani lebih menyukai buah dari penyambungan tanaman belimbing lokal dengan Bangkok Merah, karena warna, besar dan rasa buahnya jauh lebih baik dari buah belimbing jenis lokal. Sebagian besar hasil budidaya belimbing manis dijual dalam bentuk segar, sedangkan buah-buah yang tidak dipilih oleh konsumen karena kualitasnya yang tidak baik, hanya dibuang dan belum dimanfaatkan menjadi produk olahan belimbing.

Sedangkan untuk pegelolaan pasca panen, produk-produk hasil olahan blimbing macamnya masih sedikit dan berkutat di produk olahan blimbing yang sudah banyak dipasaran. Sedangkan untuk pengemasan dan logo produk juga masih snagat sederhana. Begitu pula untuk pemasaran yang selama ini hanya menggunakan cara konvesional (offline) menjadi digital (online).

Untuk itu target kegiatan pengabdian ini adalah untuk mendorong UMKM dari

Nailariza Umami - Judul Ditulis dalam font monotipe corsiva ußuran 10 Optimalisasi Nilai Tam6ah dan Digital Marketing pada Produk Olahan Blimbing di Desa Kalangan $\mathcal{N g u n u t}$ 
ibu-ibu disekitar perkebunan blimbing untuk melakukan pengemabngan produk olahan blimbing dan meningkatkan strategi pemasaran dengan digital marketing. Tujuan dari pengabdian ini adalah meningkatkan nilai tambah dengan pelatihan produk olahan kurma belimbing dan juga mengoptimalkan strategi pemasaran dengan sosialisasi dan pelatihan digital marketing

\section{METODE PELAKSANAAN}

Sesuai masalah yang dialami oleh mitra tersebut, pendekatan pelaksanaan kegiatan dilakukan dengan pendekatan metode Presman. Metode ini diawali dengan observasi dan pengamatan melalui tahapan identifikasi kemudian mencari solusi terkaid dilema yang dialami oleh mitra. Pembinaan yang dilakukan di daerah tujuan pelaksanaan program pengabdian kepada masyarakat yang melibatkan aparat desa Kalangan Ngunut. Target masyarakat yang dijadikan mitra adalah kelompok UMKM agro belimbing yang didominasi ibu rumah tangga dan petani belimbing. Dalam diskusi awal untuk persiapan dengan kelompok UMKM dan aparat desa setempat, telah berhasil merumjuskan beberapa hal : Tujuan dan maksud program pengabdian kepada masyarakat tersebut dilaksanakan, melakukan pendataan masalah yang dihadapi oleh masyarakat, melakukan diskusi tentang kegiatan tersebut, mendiskusikan lokasi dan jadwal pelaksanaan program kegiatan pengabdian kepada masyarakat,yang menghasilkan keputusan bahwa sosialisasi dan pelatihan akan dilaksanakan hari sabtu, 2 oktober 2021, bertempat di bale desa Kalangan Ngunut. Dengan jumlah pesrta yang dilibatkan ada 40 orang yang berasal dari para pelaku UMKM agro belimbing, petani belimbing dan ibu rumah tangga sekitar yang bertempat tinggal disekitar agro belimbing. Program kegiatan terdiri dari 2 sesi pemberian materi sosialisasi

kewirausahaan dan digital marketing, serta sesi pelatihan inovasi produk olahan belimbing. Sedangkan indikator keberhasilan yang harus dicapai adaalh sebagai berikut:

Tabel 1. Indikator keberhasilan

\begin{tabular}{|c|c|}
\hline Komponen & Indikator \\
\hline $\begin{array}{l}\text { Aktifitas } \\
\text { sosialisasi }\end{array}$ & $\begin{array}{l}\text { Kehadiran peserta } \\
\text { mencapai } 80 \% \\
\text { Peserta mengikuti seluruh } \\
\text { sesi dalam sosialisasi } \\
\text { yaitu sesi dan sesi } 2 \\
\text { selama } 2 \text { jam penuh }\end{array}$ \\
\hline $\begin{array}{l}\text { Aktifitas } \\
\text { Pelatihan }\end{array}$ & $\begin{array}{l}>\text { Peserta berpartisipasi } \\
\text { aktif dalam pelatihan } \\
\text { dengan smangat ikut } \\
\text { melakukan praktek } \\
>\text { Lebih dari } 50 \% \text { peserta } \\
\text { dapat mengusahai materi } \\
\text { pelatihan }\end{array}$ \\
\hline $\begin{array}{l}\text { Respon } \\
\text { Peserta }\end{array}$ & $\begin{array}{l}\text { Lebih dari } 50 \% \text { peserta } \\
\text { terlihat mendengarkan } \\
\text { dda memperhatian } \\
\text { pemaparan materi serta } \\
\text { pelatihan } \\
>25 \% \text { peserta mengajukan } \\
\text { pertanyaan }\end{array}$ \\
\hline Pengetahuan & $\begin{array}{l}\text { Kurang lebih } 60 \% \text { dari } \\
\text { peserta dapat memahami } \\
\text { pemaparan materi }\end{array}$ \\
\hline Ketrampilan & $\begin{array}{l}\text { Kurang lebih } 60 \% \text { peserta } \\
\text { mampu melakukan } \\
\text { proposi di salah satu } \\
\text { media sosial } \\
\text { Kurang lebih } 60 \% \text { peserta } \\
\text { mampu membuat kurma } \\
\text { belimbing } \\
>\text { Lebih dari } 50 \% \text { peserta } \\
\text { mampu membuat } \\
\text { pengemasan yag baik } \\
\text { untuk produk kurma } \\
\text { belimbing }\end{array}$ \\
\hline
\end{tabular}

\section{HASIL DAN PEMBAHASAN}

\section{Persiapan PkM}

Dalam tahapan persiapan ini, tim pelaksana kegiatan pengabdian kepada

Nailariza Umami - JuduLDitulis dalam font monotipe corsiva ußuran 10 Optimalisasi Nilai Tambah dan Digital Marketing pada Produk Olahan Blimbing di Desa Kalangan $\mathcal{N g}$ unut 
masyarakat melakukan diskusi degan kelompok pelaku UMKM dan aparat desa setempat dalam rangka observasi,agar kegiatan pengabdian ini benar-benar tepat sasaran sesui kebutuhan masyarakat. Dari hasil diskusi didapat bahwa desa Kalangan yang berada di kecamatan Ngunut ini memiliki potensi besar dalam budidaya buah belimbing. Sebagian besar bibit tanaman belimbing manis lokal yang dikembangkan adalah jenis Sembiring dan Blantong, sedangkan Bangkok Merah, Dewi dan Madudigunakan untuk memperbaiki kualitas buah. Sebagian besar hasil budidaya belimbing manis dijual dalam bentuk segar, sedangkan buah-buah yang tidak dipilih oleh konsumen karena kualitasnya yang tidak baik, hanya dibuang dan belum dimanfaatkan secara maksimal dalam pengolahan produk belimbing. Sedangkan untuk pegelolaan pasca panen, produk-produk hasil olahan blimbing macamnya masih sedikit dan berkutat di produk olahan blimbing yang sudah banyak dipasaran. Sedangkan untuk pengemasan dan logo produk juga masih sangat sederhana. Begitu pula untuk pemasaran yang selama ini hanya menggunakan cara konvesional (offline). Karena hal tersebut selama pandemi ini UMKM desa kalangan sangatmerasakan dampaknya, karena UMKM masih terkendala dalam hal melakukan inovasi produk dan peningkatan strategi penjualannya. Untuk itu perlu adanya peningkatan inovasi produk olahan blimbing, branding dan peningkatan strategi pemasaran menajadi digital marketing.

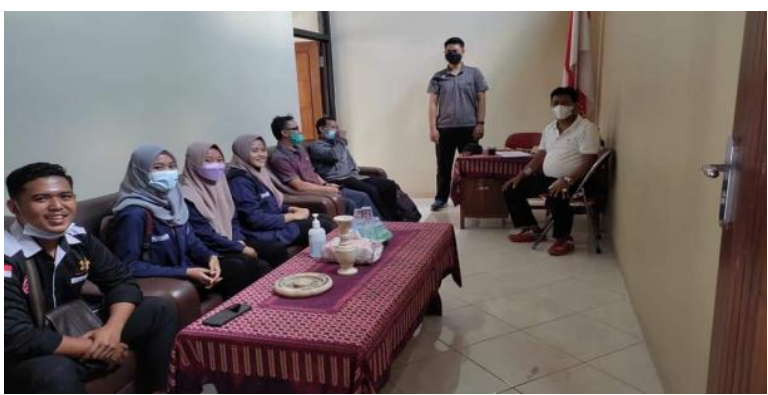

Gambar 1. Tim pengabdian melakukan koordinasi dengan pihak desa

\section{Pelaksanaan Kegiatan Sosialisasi}

Sosialisasi dilaksaakan sabtu tanggal 2 Oktober 2021. Pertama sisi pemaparan materi "Pentingnya membangkitkan kewirausahaan dimasa pandemi" yang dibawakan oleh ibu Maria Aghata W,H, M.Pd. dan sesi ke 2 dengan materi “ Pegenalan digital marketing untuk mengingkatkan strategi pemasaran" dibawakan oleh Ibu Nailariza Umami, M.Pd. Masing-masing sesi berlangsung selama 60 menit.

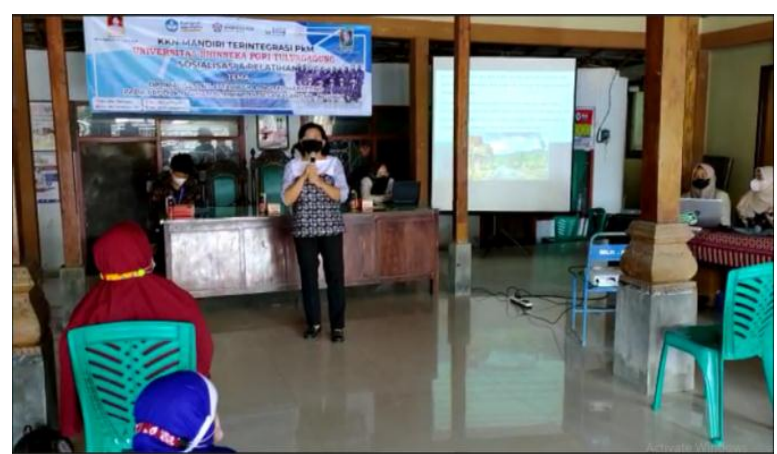

Gambar 2. Sosialisasi kewirausahaan

Dalam sesi pertama sosialisasi mengangkat materi tentang keharusan untuk segera memulihkan kewirausahaan di masa pandemi. Sektor usahapun seperti UMKM tidak luput dari dampak pandemic Covid 19. Kondisi tersebut tentunya juga sangat dirasakan oleh Sebagian besar UMKM di Desa Kalangan Ngunut. Bahkan selama pandemi banyak UMKM yang sempat berhenti beroperasi. Untuk itulah sangat perlu adanya kegiatan yang memberikan pengetahuan,smangat serta motivasi kepada pelakuk UMKM di Desa Kalangan Ngunut agar bisa bangkit dan tidak berhenti berusaha untuk dapat memajukan UMKM nya. Dengan terus berinovasi agar tetap dapat bersaing dalam persaingan usaha.

Nailariza Umami - JuduLDitulis dalam font monotipe corsiva ußuran 10 Optimalisasi Nilai Tambah dan Digital Marketing pada Produk Olahan Blimbing di Desa Kalangan $\mathcal{N g}$ gunut 


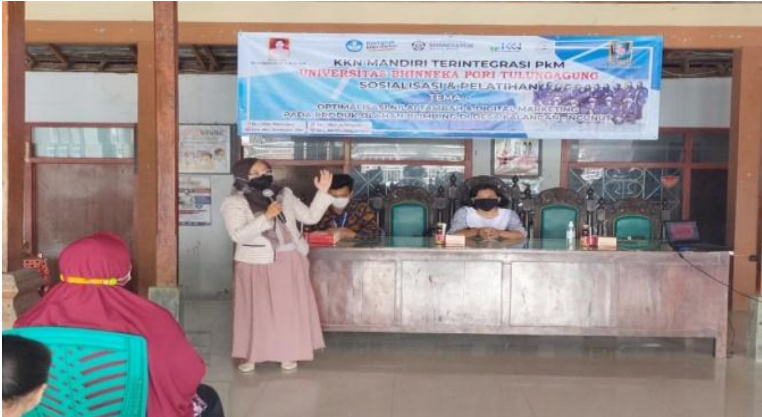

Gambar 3. Sosialisasi dan pelatihan Digital Marketing

Disesi ke dia mengangkat materi digital marketing yang merupakan pendukung dari materi di sesi pertama. Dalam kegiatan ini dijelaskan tentang pengertian,tujuan serta keunggulan digital marketing. Karena untuk dapat bangkit di masa pandemi tidak cukup hanya berinovasi terhadap produk tapi juga harus berinovasi terhadap pemasarannya. Di masa pandemi ini telah merubah tata kehidupan manusia secara drastis, semua aktifitas dan urusan manusia seluruhya dilakukan dengan cara online. Untuk itu dibidang UMKM pemasara juga harus segera beralih ke online, agar semakin menjangkau lebih luas pasar.

\section{Pelatihan inovasi produk olahan belimbing dan digital marketing}

Digital marketing merupakan kegiatan melakukan promosi brand atau produk melalui media digital. Cara ini dianggap paling efektif untuk saat ini sebagai salah satu cara pemasaran bagi semua jenis usaha, tidak terkecuali untuk UKM dan UMKM. Sebab, meskipun bisnis dijalankan dalam skala cukup kecil, menentukan strategi promosi yang tepat tetap perlu dilakukan agar bisnis semakin berkembang.

Sebagian besar pendudukan Desa Kalangan Selama ini belum begitu mengenal media sosial. Apalagi kegiatan pemasaran dengan menggunakan digital marketing sama sekali belum mereka kenal. Bagi mereka handphone yang mereka punya selama ini sepenuhnya hanya untuk alat komunikasi semata. Untuk itu sosialisasi dan pelatihan digital marketing memamg sangat mereka butuhkan untuk lebih jauh mengembangkan dan memperluas jangkauan pasar UMKM desa Kalangan Ngunut.

Dalam kegiatan ini di 30 menit pertama peserta mendapatkan materi tetang pengenalan media sosial seperti fecebook dan intragram serta salah satu marketplace yaitu shoope.Dan 30 menit kedua digunakan untuk praktek langsung membuat akun fecebook, Ig dan shoope serta mempelajari langkah awal mengunggah jualan ke Facebook,Ig dan shoope. Mereka sangat antusias dalam mempelajari dan melaksanakan pelatihan ini. Dari 40 peserta, 25 diantaranta diakir acara sudah mempunyai akun fecebook,ig dan shope. Dan Sebagian yang lain masih sebatas membuat akun fecebook dan Instagram. Karena waktu yang sangat terbatas, maka pelaksanaak pelatihan ini akan dilanjutkan dengan pembimbingan mahasiswa penuh di kediaman masing-masing.

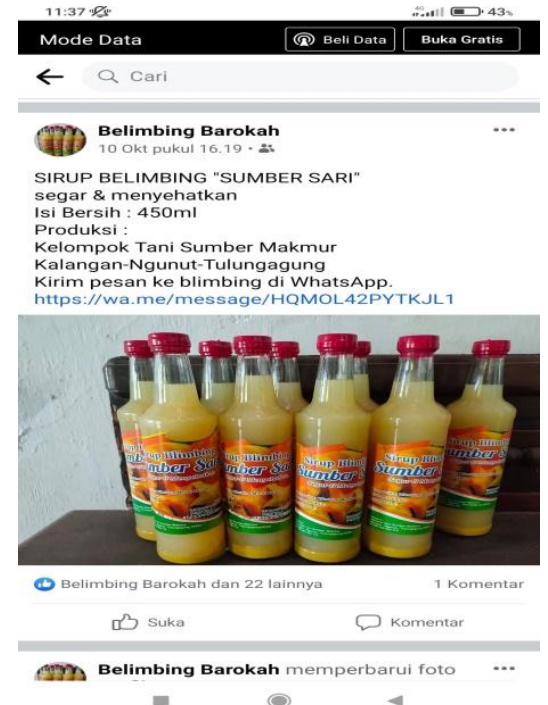

Gambar 4. Pemasaran produk masyarakat lewat akun facebook

Selanjutnya dilanjutkan ke sesi pelatihan inovasi produk olahan blimbing yaitu kurma belimbing. Dalam acara ini pemandu acara sepenuhnya dari tim pengabdian mahasiswa. Dimulai dari praktek membuat inovasi produk olahan belimbing yaitu kurma belimbing. Kurma belimbing

Nailariza Umami - Judul Ditulis dalam font monotipe corsiva ußuran 10 Optimalisasi Nilai Tam6ah dan Digital Marketing pada Produk Olahan Blimbing di Desa Kalangan $\mathcal{N g u n u t}$ 
sendiri adalah produk olahan yang berbahan dasar belimbing, gula dan air. Rasanya,bentuk dan tensturnya yang sangat menyerupai kurma,maka dari itu dinamakan kurma belimbing. Berbeda dengan manisa belimbing yang masih berair dan teksturnya masih lembek, untuk kurma belimbing sendiri lebih lembut tetapi terdapat rasa kenyal dan sudah dalam keadaan kerig tidak berair. Sebenarnya untik bahan-bahan dasar pembuatan manisan dan kurma belimbing sama persis yang mebedakan dalam proses akir, pada kurma belimbing melalui proses penjemuran sampai kurang lebih 3 hari.

Peserta dibagi mejadi 3 kelompok dan bersama-sama melaksanakn praktek. Dan saat acara usai para peserta dipersilahkan membawa produk hasil prakteknya. Diantara Sebagian besar peserta merasa sangat kagum dan sangat tertarik degan produk tersebut. Dan menyatakan bahwa akan mengembangkan produk olahan ini menjadi usaha dan memproduksi dalam jumlah banyak untuk dijual.

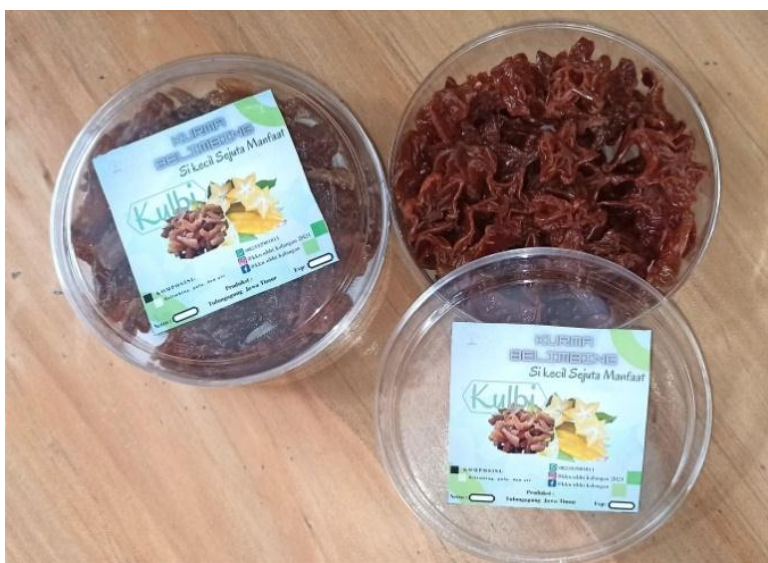

Gambar 5. Hasil produk inovasi "kurma belimbing"
Tabel 2. Pencapaian sesuai indikator

\begin{tabular}{|c|c|c|}
\hline Komponen & Indikator & Pencapaian \\
\hline $\begin{array}{l}\text { Aktifitas } \\
\text { sosialisasi }\end{array}$ & \begin{tabular}{|l} 
Kehadiran \\
peserta \\
mencapai \\
$80 \%$ \\
$>$ Peserta \\
mengikuti \\
seluruh sesi \\
dalam \\
sosialisasi \\
yaitu sesi dan \\
sesi 2 selama \\
2 jam penuh
\end{tabular} & \begin{tabular}{|l} 
Dari 45 \\
undangan 40 \\
hadir sehingga \\
tingkat \\
kehadiran \\
mencapai $88 \%$ \\
Selama \\
sosialisasi dan \\
pelatihan \\
peserta tidak \\
ada yang ijin \\
pulang terlebih \\
dulu,sehinga \\
sampai akir \\
peserta masih \\
40 orang
\end{tabular} \\
\hline $\begin{array}{l}\text { Aktifitas } \\
\text { Pelatihan }\end{array}$ & $\begin{array}{l}\text { Peserta } \\
\text { berpartisipasi } \\
\text { aktif dalam } \\
\text { pelatihan } \\
\text { dengan } \\
\text { smangat ikut } \\
\text { melakukan } \\
\text { praktek } \\
\text { Lebih dari } \\
\text { 50\% peserta } \\
\text { dapat } \\
\text { mengusahai } \\
\text { materi } \\
\text { pelatihan }\end{array}$ & \begin{tabular}{|l} 
Peserta dengan \\
berkelompok \\
melakukan \\
praktek sampai \\
selesai \\
Semua peserta \\
dapat dapat \\
mebuat olah \\
kurma \\
belimbing \\
Untuk pelatihan \\
pemasaran \\
dengan digital \\
marketing \\
hanya sampai \\
pada praktek \\
pembuatan \\
media sosial \\
sehingga \\
tingkat \\
keberhasilan \\
masih sekitar \\
$40 \%$
\end{tabular} \\
\hline $\begin{array}{l}\text { Respon } \\
\text { Peserta }\end{array}$ & $\begin{array}{l}\text { Lebih dari } \\
50 \% \text { peserta } \\
\text { terlihat } \\
\text { memperhatian } \\
\text { pemaparan } \\
\text { materi serta } \\
\text { pelatihan } \\
25 \% \text { peserta } \\
\text { mengajukan } \\
\text { pertanyaan }\end{array}$ & $\begin{array}{l}1 \text { jam pertama } \\
\text { peserta masih } \\
\text { sangat } \\
\text { memperhatikan, } \\
\text { disaat di sesi ke } \\
2 \text { masuk materi } \\
\text { digital } \\
\text { marketing yang } \\
\text { mungkin masih } \\
\text { asing bagi } \\
\text { mereka,peserta } \\
\text { terlihat mulai } \\
\text { kurang } \\
\text { memperhatikan } \\
\text { dan bosan }\end{array}$ \\
\hline
\end{tabular}




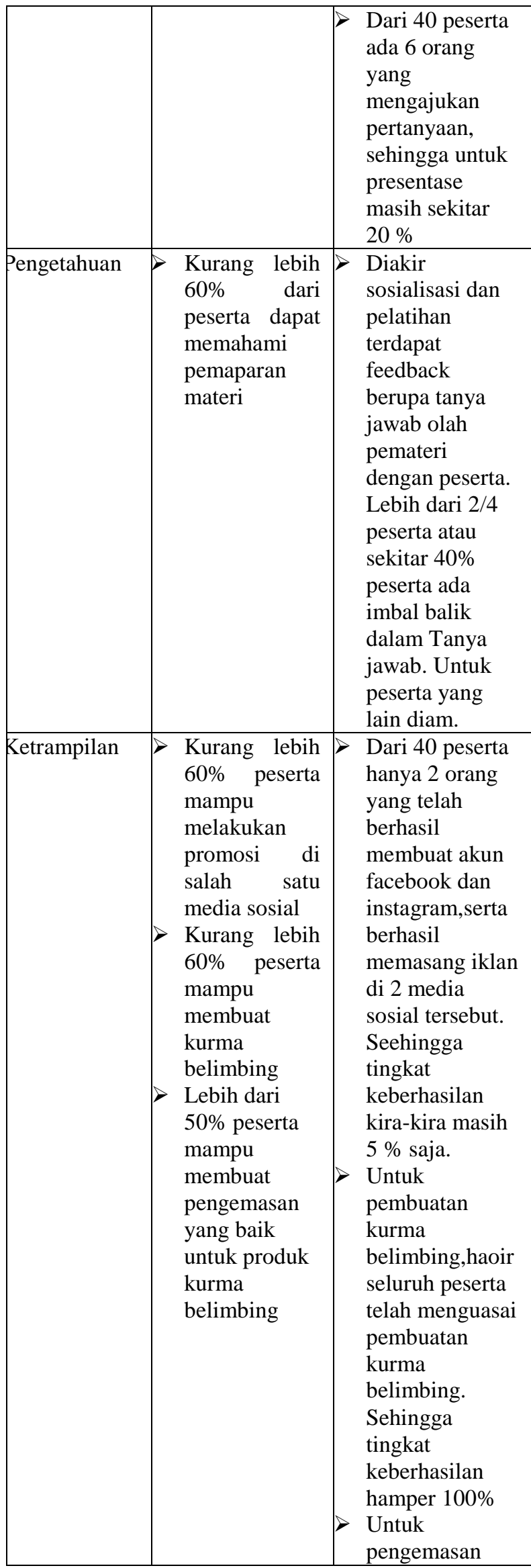

\begin{tabular}{|l|l|l|}
\hline & tidak semua \\
& dapat trampil \\
mengemas \\
produk dengan \\
rapi
\end{tabular}

Program sosialisasi pelatihan dapat dikatakan efektif apabila memberikan dampak positif terhadap tingkat produktivitas usaha dan meningkatkan pendapatan mereka secara ekonomi. Namun perlu dicatat di sini bahwa meskipun program pelatihan tersebut belum optimal, namun sekurang-kurangnya telah memberikan pengenalan tentang bagaimana pentingnya membangkitkan kewarausahaan dimasa pandemi ini serta pentingnya terus berinovasi untuk menciptakan produk-produk olahan blimbing untuk menambah keanekaragamaan produk olahan belimbing. Dan juga pelatihan ini telah memberikan pemahaman pula bagaimana petingnya terus meningkatkan strategi pemasaran di jaman online ini, yaitu dengan digital marketing. Yang nantinya sosialisasi dan pelatihan ini diharapkan akan terus dipakai masyarakat dan bermanfaat untuk peningkatan usaha UMKM di Desa Kalangan Kecamatan Ngunut Kabupaten Tulungagung.

\section{KESIMPULAN}

Berdasarkan hasil kegiatan pengabdian yang telah dilakukan, maka dapat disimpulkan bahwa:

1. Adanya peningkatan pengetahuan kelompok masyarakat di Desa Kalangan Ngunut digital marketing dan inovasi produk olahan belimbing.

2. Masyarakat di Desa Kalangan Ngunut dapat langsung mempraktekan Digital Marketing dan inovasi produk belimbing mulai dari membuat produk olahan berupa kurma belimbing sampai pada pengemasan dan pemberian label.

3. Strategi pemulihan ekonomi saat pandemic Covid-19 tidak hanya tanggung jawab pemerintah,namun juga diperlukan 
peran serta masyarakat bersama-sama dalam memperkuat ketahanan ekonomi rumah tangga.Akan lebih bijak bila sebuah masyarakatnya mampu melihat masalah menjadi sebuah peluang, bisa menjawab tantangan,serta tangguh menghadapai semua ancaman, salah satu cara yang dirasa cukup ampuh adalah menumbuhkan dan menguatkan jiwa wirausaha (entrepreneur). Diharapkan dengan menguatnya pemikiran serta tindakan kewirausahaan yang semakin massif,masyarakat dapat hidup mandiri da bertahan sekalipun ditengah situasi sulit seperti sekarang ini. Enterpreneurship memiliki dampak positif bagi suatu perekonomian dan masyarakat, slah satunya dampak terpenting dari entrepreneurship adalah penyediaan lapangan pekerjaan. Inovasi merupakan alas an kedua yang memberikan dampak positif bagi kekuatan ekonomi dan masyarakat di tengah wacana "era kenormalan baru". Inovasi berkaitan dengan proses menciptakan sesuatu yang baru den membantu individu untuk bekerja secara efektif dan efisien.

\section{Ucapan Terima Kasih}

Terima kasih kamiucapkan kepada Universitas Bhinneka PGRI yang telah memberikan biaya penuh dalam pelaksanaan pengabdian masyarakat ini

\section{DAFTAR PUSTAKA}

Achmad Dafid Husni, Any mardiyanti, A. Z., Arif Gema Setiawan, Fatchur Rochman Kabarudin, Nuriyah, L., Hakim, L. Merry Amanda Permatasari, Mufidatul Nizak, Moch Dani Septiyan, M. J. M, Myta Fauziah Samsu, Novita Emila Tisnawati, Nurul Alfiaturrohmaniah, Rico Ryan Ernanda, V.Q. A.R \& Lely Ika Mariyati. (2019). Pengabdian Masyarakat di Desa Keboan Anom Tahun 2019
(Rohman Dijaya(ed)). UMSIDA

Press. https://drpm.umsida.ac.id/wpcontent/uploads/2020/09/Buku-KKNKeboananom-2019

Dany Saputra, Survei BI: 87,5 Persen UMKM Indonesia Terdampak Pandemi Covid 19. Diakses pada 1 September 2021 darihttps://ekonomi.bisnis.com/read/ 20210319/9/1370022/survei-bi-875persen-umkm-indonesia-terdampakpandemi-covid-19.

Hanun, H. R, Fitriyah. H, \& Azzara, R. (2020). Kemandirian Ekonomi Melalui Optimalisasi Peran Karang Taruna. Berdikari, (08(02), 115-122. https://journal.umy.ac.id/index.php/ berdikari/article/view/8881/5640

Mushlihin Al-Hafizh, "Pemberdayaan Ekonomi Masyarakat", lihat dalam http://www. referensimakalah.com/2012/12/peng ertian-pemberdayaan-ekonomiumat.html diakses tanggal 18 Agustus 2018.

Sukmasetya, P., Haryanto, T., Sadewi, F.A. Maulida, R.B.G, Aliudin, H. S, \& Sugiarto, B. (2020). Pemanfaatan Digital Marketing sebagai Media Pemasaran Global untuk Meningkatkan Penjualan Produk pada Home Industry, Community, Empowerment, 5(2), 28-35. https://doi.org/10.31603/ce.v5i2.351 4

Supriyanto, A. (2015). Profil DEsa Keboan Anom Gedangan Sidoarjo. https://kkndesakeboananom.blogspo t.com/2015/08/pos-bindu.html

Nailariza Umami - JuduLDitulis dalam font monotipe corsiva ußuran 10 Optimalisasi Nilai Tambah dan Digital Marketing pada Produk Olahan Blimbing di Desa Kalangan $\mathcal{N g}$ gunut 